\title{
Iron Metabolism in
}

\section{Copper-Deficient Swine}

\author{
G. Richard Lee, Sergio Nacht, John N. Lukens, and G. E. Cartwright \\ From the Department of Medicine, University of Utah College of Medicine, \\ Salt Lake City, Utah 84112
}

A в S T R A C T The way in which iron is handled by the duodenal mucosa, the reticuloendothelial system, the hepatic parenchymal cell, and the normoblast was investigated in copper-deficient swine.

Copper-deficient swine failed to absorb dietary iron at the normal rate. Increased amounts of stainable iron were observed in fixed sections of duodenum from such animals. When ${ }^{59}$ iron was administered orally, the mucosa of copper-deficient animals extracted iron from the duodenal lumen at the normal rate, but the subsequent transfer to plasma was impaired.

When intramuscular iron supplements were given to copper-deficient pigs, increased amounts of iron were found in the reticuloendothelial system, the hepatic parenchymal cells, and in normoblasts (sideroblasts). Hypoferremia was observed in the early stages of copper deficiency, even though iron stores were normal or increased. When red cells that were damaged by prolonged storage were administered, the reticuloendothelial system failed to extract and transfer the erythrocyte iron to the plasma at the normal rate. Administration of copper to copper-deficient animals with normal iron stores resulted in a prompt increase in the plasma iron.

The observed abnormalities in iron metabolism are best explained by an impaired ability of the duodenal mucosa, the reticuloendothelial system, and the hepatic parenchymal cell to release iron to the plasma. It is suggested that copper is essential to the normal release of iron from these tissues.

Dr. G. Richard Lee is a Markle Scholar in Academic Medicine.

Received for publication 7 March 1968 and in revised form 8 May 1968.
This concept is compatible with the suggestion made by others that the transfer of iron from tissues to plasma requires the enzymatic oxidation of ferrous iron, and that the plasma copper protein, ceruloplasmin, is the enzyme (ferroxidase) which catalyzes the reaction.

Because excessive amounts of iron were found in normoblasts, it is suggested that an additional defect in iron metabolism affects these cells and plays a major role in the development of anemia. As a result of the proposed defect, iron cannot be incorporated into hemoglobin and, instead, accumulates as nonhemoglobin iron.

\section{INTRODUCTION}

The severe anemia associated with copper deficiency in swine has been characterized as hypochromic and microcytic $(1,2)$. Since anemia of this type usually is due to a defect in hemoglobin synthesis, a role for copper in the biosynthesis of hemoglobin has been proposed. However, neither the nature of the defect nor the role for copper has been elucidated.

Defects in hemoglobin synthesis may be classified into three categories: (1) abnormalities in the biosynthesis of protoporphyrin and heme; (2) abnormalities in the metabolism of iron; and (3) abnormalities in the biosynthesis of globin. In an investigation recently reported from this laboratory (3), the pathways of porphyrin and heme synthesis in erythrocytes from copper-deficient swine were found to be intact.

Impaired absorption of iron from the gastrointestinal tract has been observed previously in copper-deficient swine along with hypoferremia and 
an increase in the total iron-binding capacity (4). Because of the impaired absorption of iron, such animals were actually deficient in iron even though large amounts of iron were supplied in the diet. However, the parenteral administration of iron failed either to prevent or to alleviate the anemia. Thus, failure to absorb iron did not appear to be the only factor involved in the pathogenesis of the anemia.

The purposes of the present investigation were: (1) to gain a clearer understanding of the defect in iron absorption; (2) to search for abnormalities in the way iron is handled by other tissues, especially the reticuloendothelial system, the hepatic parenchymal cell, and the normoblast; and (3) to determine if the defects in iron metabolism constituted an adequate explanation for the anemia. Because of the tissue deficiency of iron that occurs in copper-deficient swine fed iron by the oral route, it is not possible to evaluate iron metabolism in tissues other than the duodenal mucosa. For this reason, studies were made in pigs given iron intramuscularly in an amount calculated to maintain the total body iron within normal limits. The results are compared with those obtained from studies in copper-deficient pigs given iron by mouth, in iron deficient pigs, and in controls.

\section{METHODS}

The 82 pigs used in this study were obtained at 3-5 days of age. They were of mixed breed and were purchased from a single breeder in litters of 6-10 animals.

The experimental diet consisted of canned condensed milk with no supplements other than those described below. Details of diet preparation have been reported previously (1). On the basis of the nature and route of the iron and copper supplements they received, the pigs were divided into five experimental groups: (1) control (oral iron), (2) control (i.m. iron), (3) iron deficient, (4) copper deficient (oral iron), and (5) copper deficient (i.m. iron). Groups 1,2 , and 3 received $0.5 \mathrm{mg}$ of copper as copper sulfate per $\mathrm{kg}$ of body wt per day with the diet. Control (oral iron) and copper-deficient (oral iron) swine were given $30 \mathrm{mg}$ of iron as ferrous chloride per $\mathrm{kg}$ of body wt per day with the diet. Control (i.m. iron) and copper-deficient (i.m. iron) pigs received a total of 1.2 or $2.0 \mathrm{~g}$ of iron in multiple intramuscular injections, between 10 and 28 days of age. The intramuscular iron preparation used was Pigdex 100 (colloidal iron oxide stabilized with a low viscosity dextrin). ${ }^{1}$ No iron supplements were given to the irondeficient group. In some experiments, no difference was

\footnotetext{
1 American Cyanamid Co., Princeton, N. J.
}

apparent between the two control groups, and they were combined for statistical purposes.

The routine hematologic methods used in this study and the methods for determining plasma iron, plasma iron-binding capacity, and bone marrow iron have been published (5). Fixed tissue sections were stained for iron by the method of Gomori (6). Tissue iron concentration was determined after wet digestions with sulfuric, nitric, and perchloric acids (3), and the determined value was corrected for tissue hemoglobin concentration by the method of Andersen and Shoemaker (7).

\section{RESULTS}

Effect of intramuscular iron supplements on the anemia of copper deficiency

The volume of packed red cells and the corpuscular constants. Values for the volume of packed red cells (VPRC) and the corpuscular constants during the development of copper deficiency are depicted in Fig. 1. Of the 33 copper-deficient pigs, 20 were given iron supplements by mouth and 13 were given iron intramuscularly. Both types of iron supplementation were used in the control group, which consisted of 17 pigs.

In the copper-deficient (oral iron) group, a decrease in the VPRC became evident by $6 \mathrm{wk}$ of age. The VPRC continued to decrease in a rapid and linear fashion until the pigs were 10-11 wk of age, at which point some deaths began to occur among the most anemic animals. These deaths account for the apparent tendency of the VPRC to become stable at about $20 \mathrm{ml} / 100 \mathrm{ml}$. Microcytosis, as measured by the mean corpuscular volume (MCV), was an early development and its severity paralleled that of the anemia. Significant hypochromia, as measured by the mean corpuscular hemoglobin concentration ( $\mathrm{MCHC})$, was a later development, appearing at 10-11 wk of age.

In the copper-deficient (i.m. iron) group, initial values for the VPRC were greater than in the control group, probably because of the residual effects of neonatal iron deficiency in some of the control pigs. Thereafter, anemia progressed at a rate similar to that observed in copper-deficient (oral iron) pigs, and by 13 wk of age the anemia was equally severe in both deficient groups. The intramuscular administration of iron lessened in degree, but did not prevent the development of hypochromia and microcytosis; values for the corpuscular constants in the group receiving in- 


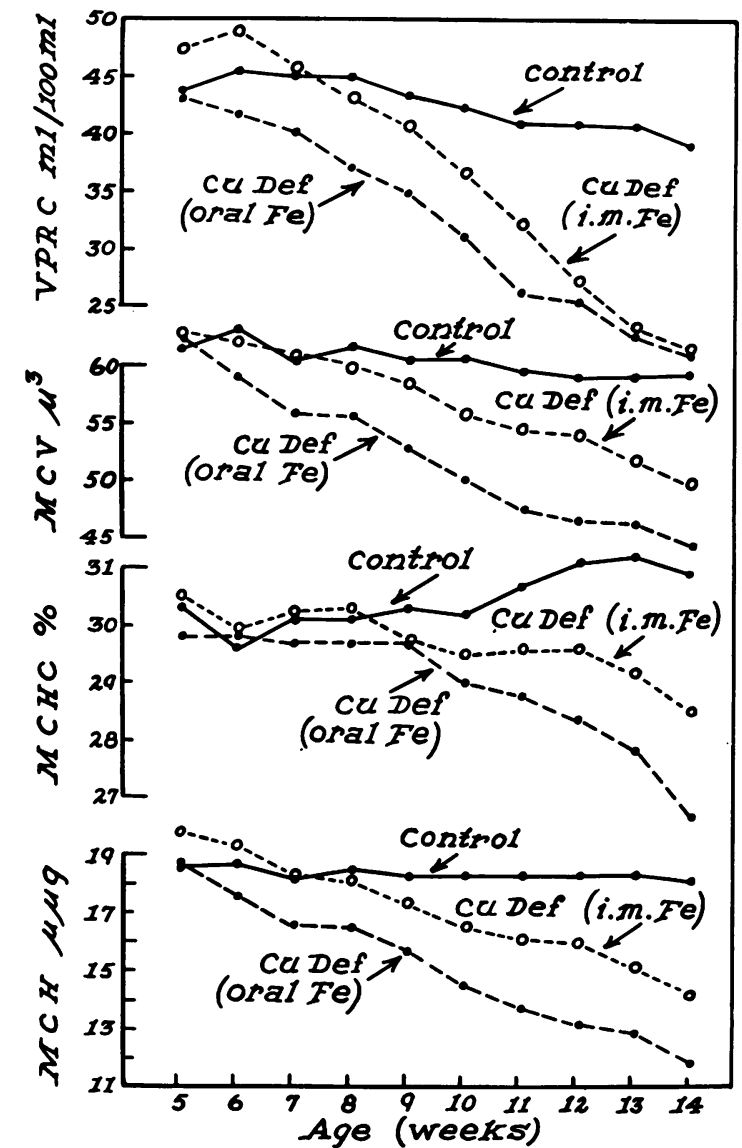

FIGURE 1 Changes in volume of packed red cells (VPRC), mean corpuscular volume (MCV), mean corpuscular hemoglobin concentration ( $\mathrm{MCHC}$ ), and mean corpuscular hemoglobin $(\mathrm{MCH})$ with development of copper deficiency. Hypochromic, microcytic anemia developed in copper-deficient pigs, regardless of the route by which iron was administered.

tramuscular iron supplements were intermediate between those of the control group and of the group receiving iron with the diet. At $13 \mathrm{wk}$ of age, all three groups differed significantly from one another $(P<0.001)$ with respect to the $\mathrm{MCV}$, the $\mathrm{MCHC}$, and the mean corpuscular hemoglobin.

Plasma Iron. The plasma iron concentration and the total plasma iron-binding capacity were determined weekly in 12 control, 14 copper-deficient (oral iron), and 14 copper-deficient (i.m. iron) pigs (Fig. 2). In copper-deficient (oral iron) pigs, the plasma iron level decreased progressively until the pigs were about 12 wk of age; thereafter, it tended to increase. In copper-deficient (i.m. iron) pigs, hypoferremia was observed between the ages of 8 and $11 \mathrm{wk}$. Thereafter, the plasma iron values returned to normal. Thus, in both copper-deficient groups, three phases could be defined with respect to the changes in the plasma iron: an initial phase in which the plasma iron was normal; a hypoferremic phase; and a terminal phase during which the plasma iron increased. These phases differed in degree and duration in the two groups. Additional data concerning the hypoferremic phase in the copper-deficient (i.m. iron) group and the terminal phase in both groups will be presented in later sections.

The total plasma iron-binding capacity was increased throughout the entire course in the copperdeficient (oral iron) group. Values observed in the copper-deficient (i.m. iron) group did not differ significantly from those in the control group.

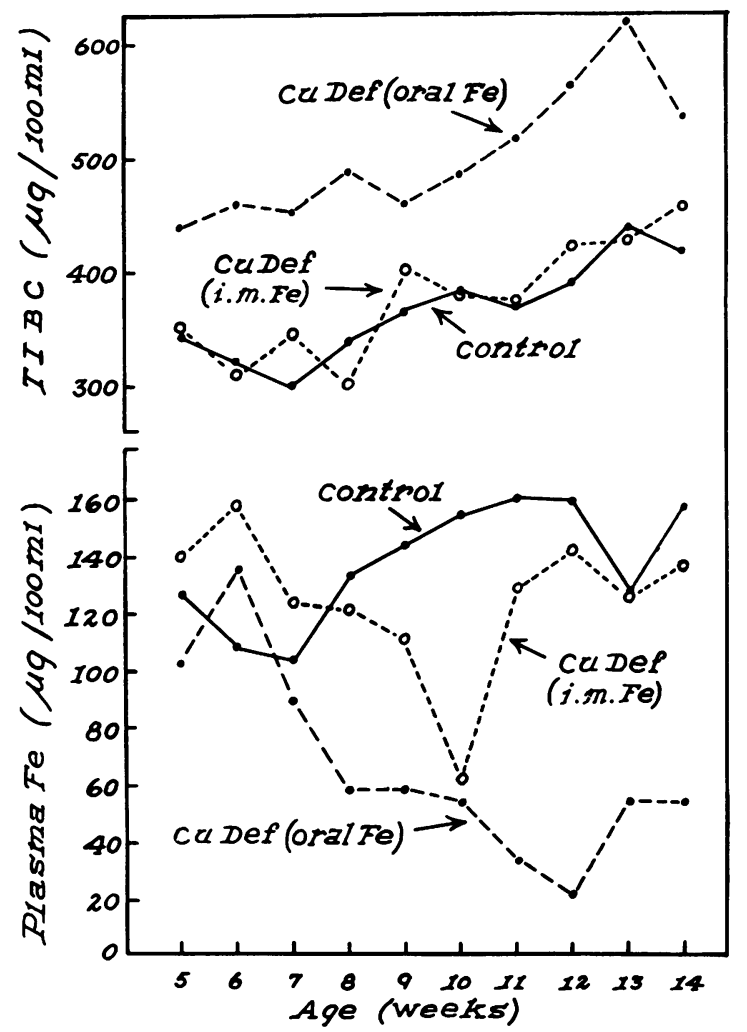

Figure 2 Changes in plasma iron ( $\mathrm{Fe}$ ) and total ironbinding capacity (TIBC) with development of copper deficiency. Hypoferremia and an increase in TIBC were observed in copper-deficient (oral iron) pigs. Transient hypoferremia with no change in TIBC was found in copper-deficient (I.M. iron) pigs. 
TABLE I

Tissue Iron in Copper-Deficient and Controi Swine

\begin{tabular}{|c|c|c|c|c|c|c|}
\hline & & $\begin{array}{l}\text { Controls } \\
\text { (oral iron) }\end{array}$ & $\begin{array}{l}\text { Controls } \\
\text { (i.m. iron) }\end{array}$ & $\begin{array}{c}\text { Iron } \\
\text { deficient }\end{array}$ & $\begin{array}{l}\text { Copper } \\
\text { deficient } \\
\text { (oral iron) }\end{array}$ & $\begin{array}{l}\text { Copper } \\
\text { deficient } \\
\text { (i.m. iron) }\end{array}$ \\
\hline & & s.....6 & 9 & 5 & 14 & 10 \\
\hline & Concentration & & & & & \\
\hline \multirow[t]{2}{*}{ Liver iron } & $\mu g / g$ & $149 \pm 8$ & $1738 \pm 293$ & $18 \pm 1.5$ & $61 \pm 13$ & $1478 \pm 182$ \\
\hline & $\begin{array}{l}\text { Total } \\
\quad m g / \text { organ }\end{array}$ & $54 \pm 17$ & $622 \pm 65$ & $2.1 \pm 0.2$ & $24 \pm 5.7$ & $632 \pm 85$ \\
\hline \multirow[t]{2}{*}{ Spleen iron } & $\begin{array}{c}\text { Concentration } \\
\mu g / g\end{array}$ & $88 \pm 18$ & $140 \pm 21$ & $104 \pm 6$ & $187 \pm 13.6$ & $676 \pm 108$ \\
\hline & $\begin{array}{l}\text { Total } \\
\quad m g / \text { organ }\end{array}$ & $2.0 \pm 0.2$ & $5.5 \pm 0.7$ & $0.9 \pm 0.1$ & $6.3 \pm 0.9$ & $20 \pm 2.3$ \\
\hline Red cell iron, $m g$, (Total) & & $661 \pm 63$ & $789 \pm 59$ & $69 \pm 7$ & $239 \pm 15$ & $300 \pm 30$ \\
\hline "Total" body iron, $m g$ & & $715 \pm 71$ & $1415 \pm 62$ & $72 \pm 7$ & $266 \pm 18$ & $949 \pm 105$ \\
\hline Body weight, $k g$ & & $16.4 \pm 2.0$ & $20.3 \pm 1.6$ & $4.4 \pm 0.5$ & $14.8 \pm 0.7$ & $16.8 \pm 1.2$ \\
\hline $\begin{array}{l}\text { "Total" body iron concentration, } \\
m g / k g \text { of body wt) }\end{array}$ & & $45 \pm 3$ & $73 \pm 7$ & $17 \pm 1.3$ & $18 \pm 0.9$ & $59 \pm 7$ \\
\hline
\end{tabular}

Values are means \pm SEM.

\section{Duodenal mucosa}

Iron absorption. An estimate of total body iron content was made in pigs from each of the experimental groups. In the animals that received oral iron supplements, this estimate was used as a measure of the amount of iron absorbed during the observation period. Estimated "total" body iron was calculated by summing the amounts of iron in the liver, the spleen, and the circulating erythrocytes. The assumption was made that a relatively small proportion of the total body iron would be found outside of these three sites. The concentration of iron in the liver and spleen was determined directly on tissues obtained when the animals were killed (at 12-17 wk of age, except in the case of the iron-deficient pigs, who became anemic more quickly and were, therefore, killed at $6-8$ wk of age). The total red cell iron was calculated from the blood hemoglobin concentration, the estimated blood volume (8), and the known iron content of hemoglobin.

The copper-deficient (oral iron) pigs were found to be severely iron deficient. Their "total" body iron concentration, liver iron content, and erythrocyte iron content were considerably lower than in control (oral iron) pigs; in fact, the "total" body iron concentration was of the same order of magnitude as the values found in the iron- deficient group (Table I). When iron supplements were given intramuscularly, copper-deficient pigs did not become iron deficient and their "total" body iron concentration was comparable with that of the control group.

Iron in fixed sections of duodenum. Sections of proximal duodenum were obtained at autopsy and stained for iron. In specimens from pigs that had received iron with the diet, Prussian blue positive material was seen in two locations: in the lamina propria as large granules within macrophages, and within the columnar epithelial cells as a line of fine granules (Fig. 3). No stainable granules were seen in mucosal specimens from animals given iron supplements exclusively by the intramuscular route; thus, the visible iron appeared to be of dietary origin, rather than part of a pool in equilibrium with other body stores.

The amount of iron found in the mucosa was considerably greater in copper-deficient (oral iron) pigs than in controls. The amount of iron in each specimen was estimated semiquantitatively on a scale from 0 to $4+$. On this scale, mucosa from control (oral iron) pigs contained a trace to $1+$ stainable iron, whereas specimens from copperdeficient (oral iron) pigs were scored as 3 to $4+$. This observation suggested that the barrier to the absorption of iron in the copper-deficient ani- 


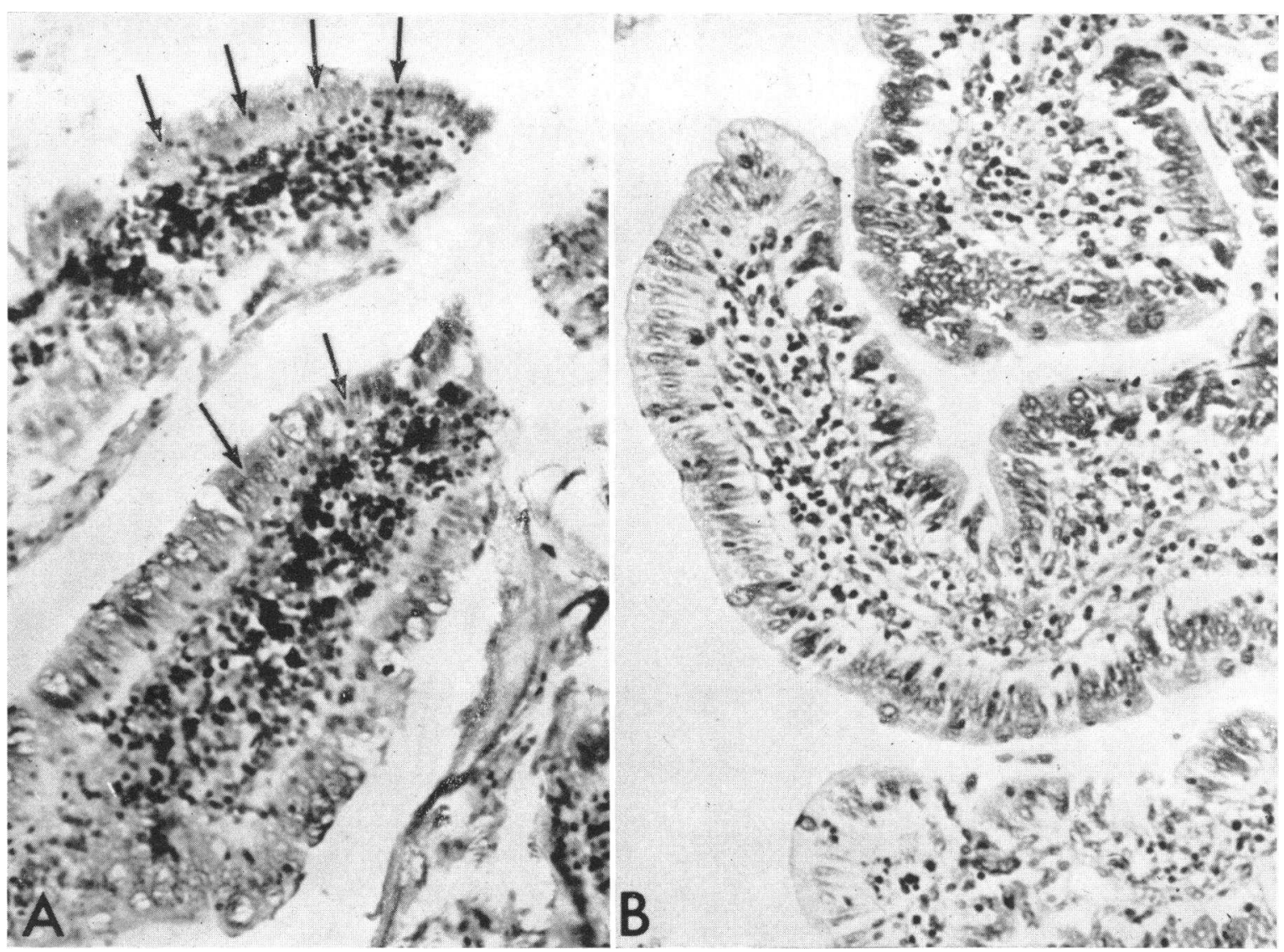

FigURE 3 Iron stains of mucosa from a copper-deficient (oral iron) pig $(A)$ and a control (oral iron) pig $(B)$. In the copper-deficient animal, large amounts of iron were seen in the lamina propria and within epithelial cells. Since the iron is seen more easily in a colored reproduction, the arrows are inserted to indicate the location of epithelial iron.

mals did not lie between the intestinal lumen and the duodenal mucosa, but at a subsequent site in the absorption pathway.

Changes in mucosal iron after a test meal. The above hypothesis was studied further by measuring mucosal radioactivity after the administration of test meals containing ${ }^{59}$ iron. These experiments were performed when the pigs were between 90 and 110 days old, at which time the copper-deficient pigs were severely anemic (VPRC less than $25 \mathrm{ml} / 100 \mathrm{ml}$ ). After a $48 \mathrm{hr}$ fast each pig was fed, by stomach tube, a test meal consisting of 1 $\mathrm{mg}$ of iron as ferrous chloride labeled with 5-10 $\mu \mathrm{c}$ of ${ }^{59} \mathrm{Fe}$. At varying time intervals thereafter, the pigs were killed by exsanguination. The proximal duodenum was excised, opened, and washed with $0.01 \mathrm{~m}$ EDTA in saline. Mucosa was scraped free from underlying layers with a glass slide (9), suspended and washed in EDTA-saline, and centrifuged at $1120 \mathrm{~g}$. The volume of packed mucosa was measured in a graduated centrifuge tube. Radioactivity was assayed by crystal scintillation counting, and mucosal iron content was calculated from the specific activity of the iron in the test meal.

In control animals, mucosal radioactivity increased to a maximum value $2-3 \mathrm{hr}$ after the test meal, and then decreased rapidly, so that little radioactivity remained in the mucosa 8 and $24 \mathrm{hr}$ after the meal (Fig. 4). In iron-deficient pigs, the pattern was similar to that seen in controls, except that the maximum value was reached somewhat more quickly, and was of lesser magnitude.

The pattern observed in copper-deficient animals was quite different. The magnitude of the initial peak was greater, and the subsequent de- 
crease was considerably less, leaving much larger amounts of test meal iron in the mucosa after 8 and $24 \mathrm{hr}$. Mucosal radioactivity at $24 \mathrm{hr}$ was about half as great in copper-deficient (i.m. iron) pigs as it was in copper-deficient (oral iron) pigs.

Subcellular distribution of mucosal radioiron. To define more clearly the nature of the iron retained by the mucosa, a crude subcellular fractionation was performed. Mucosa was homogenized with high-frequency sound." A "sedimentable" fraction was recovered by centrifuging the homogenate at $9000 \mathrm{~g}$ for $30 \mathrm{~min}$. The supernatant solution was heated at $75^{\circ} \mathrm{C}$ for $5 \mathrm{~min}$, and the precipitate was harvested and designated "heatlabile proteins." Perchloric acid (final concentration, $2 \%$ ) or ammonium sulfate (60\% saturation) was added to the supernatant solution, and the precipitate so obtained was designated "ferritin." All radioactivity in this fraction was excluded by Sephadex G-200 gel and could be sedimented at $90,000 \mathrm{~g}$ in a preparative ultracentrifuge. The supernatant solution which remained after "ferritin" precipitation was termed the "nonprotein" fraction. Radioactivity in each of the four fractions was assayed.

The distribution of radioactivity among these mucosal fractions was determined in one animal from each group at $2 \mathrm{hr}$ after the test meal, and in

${ }^{2}$ Sonifer, Branson Instruments, Inc., Stamford, Conn.

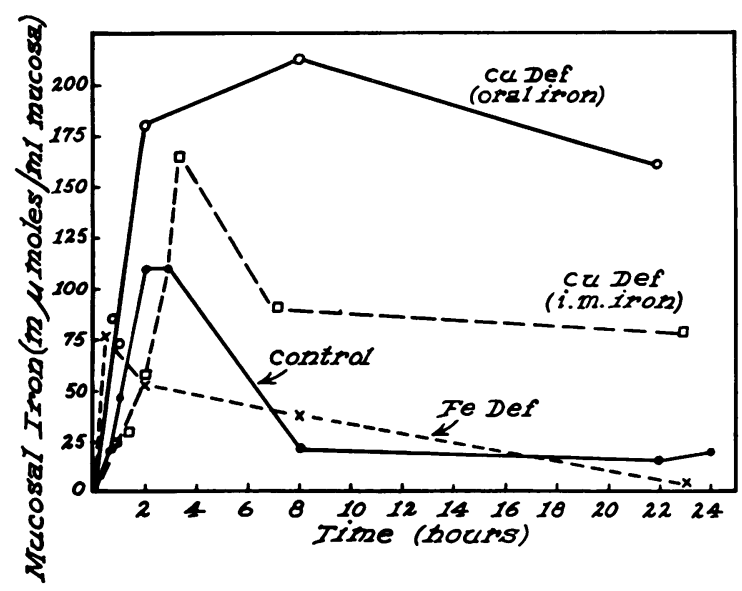

Figure 4 Mucosal iron after a test meal containing ${ }^{59}$ iron. Note the excessive retention of iron at $22 \mathrm{hr}$ in both copper-deficient groups.

one from each group at $24 \mathrm{hr}$ (Table II). The "ferritin" fraction contained most of the radioactivity, both at 2 and at $24 \mathrm{hr}$, in all pigs except those in the iron-deficient group. In these, most of the radioactivity was in the nonprotein fraction at $2 \mathrm{hr}$ and in the sedimentable fraction at 24 hr.

In copper-deficient pigs, an increased amount of mucosal radioiron was found in all four subcellular fractions at $24 \mathrm{hr}$; most notably in the ferritin fraction.

TABLE II

Subcellular Distribution of Mucosal Iron* After a Test Meal

\begin{tabular}{cccccc}
\hline & & \multicolumn{3}{c}{ Subcellular fraction } \\
\cline { 5 - 6 } Group & Time after test meal & Sedimentable & Heat-labile & Ferritin & NonProtein \\
\hline Control & 2 & 18.3 & 5.5 & 81.9 & 4.2 \\
& 24 & 4.8 & 1.7 & 6.2 & 1.6 \\
$\begin{array}{c}\text { Copper deficient } \\
\text { oral iron }\end{array}$ & 2 & 26 & 7.9 & 143.0 & 3.6 \\
$\begin{array}{c}\text { Copper deficient } \\
\text { i.m. iron }\end{array}$ & 24 & 39.8 & 15.2 & 97.4 & 6.3 \\
& 2 & 5.9 & 3.2 & 33.1 & 10.8 \\
Iron deficient & 24 & 19.0 & 6.9 & 42.7 & 5.3 \\
& 24 & 12.3 & 4.6 & 7.7 & 27.7
\end{tabular}

\footnotetext{
* In $\mathrm{m} \mu$ moles of $\mathrm{Fe} / \mathrm{ml}$ of mucosa.
} 
The reticuloendothelial system

Splenic and hepatic iron. When iron deficiency develops in an otherwise normal animal, iron in the liver and spleen is depleted before anemia develops. In copper-deficient (oral iron) animals, on the other hand, a relatively large amount of iron was retained by these organs (Table I). The copper-deficient (oral iron) group and the iron-deficient group were equally iron deficient as measured by "total" body iron concentration. Nevertheless, the liver iron concentration in copperdeficient (oral iron) pigs was more than three times as great as in iron-deficient pigs. The splenic iron concentration of copper-deficient (oral iron) pigs was also significantly greater than that of iron-deficient pigs. In fact, copperdeficient pigs retained more iron in their spleens than did controls. Still greater iron retention by the spleen occurred in the copper-deficient group that received intramuscular iron supplements. These findings suggested that in copper-deficient pigs, the reticuloendothelial system, like the duodenal mucosa, retains iron.

Hypoferremia with normal iron stores. Changes in the plasma iron with time in a typical

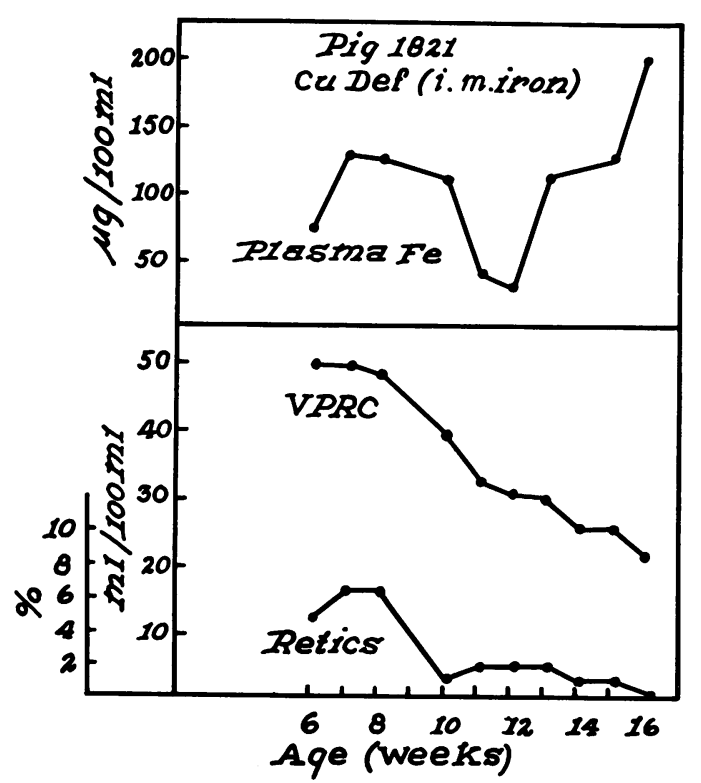

FIgURE 5 Changes in plasma iron in a single copperdeficient (I.M. iron) pig with the development of copper deficiency. A 2 wk period of hypoferremia was observed followed by an increase in plasma iron to hyperferremic levels.

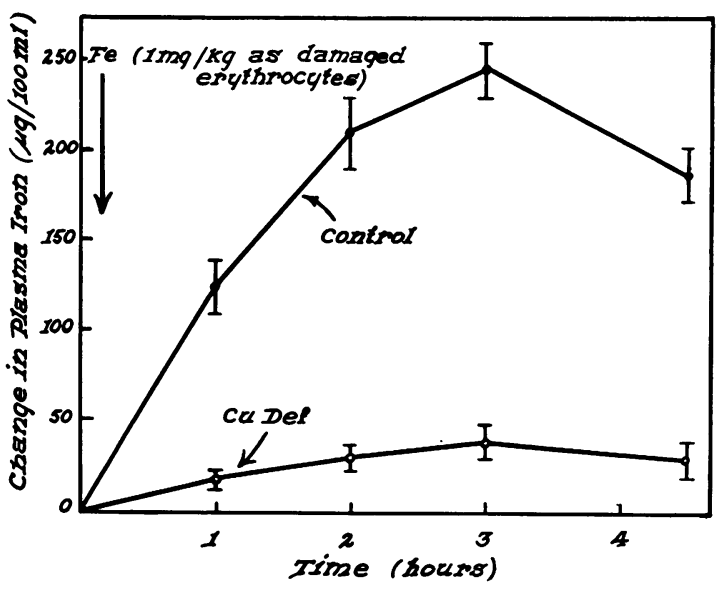

Figure 6 The effect of an infusion of damaged red cells on plasma iron. Values for the mean \pm SEM are depicted at each point. The infusion induced relatively little change in the copper-deficient pigs.

copper-deficient (i.m. iron) animal are depicted in Fig. 5. A 2 wk period of hypoferremia was observed, followed by a rise to above normal levels. This pattern was also observed in other animals in this group, but the age at which the hypoferremia occurred varied. Thus, the calculation of mean values at a single age, as was done in constructing Fig. 2, tended to obscure the finding. In Fig. 2, hypoferremia was clearly evident only at week 10 .

To document this phenomenon more clearly, the lowest plasma iron out of a series of weekly determinations over a 3 month period was recorded for each pig. The mean "lowest" plasma iron value in 11 control pigs was $117 \pm 7.3 \mu \mathrm{g} /$ $100 \mathrm{ml}$ (mean $\pm \mathrm{SEM}$ ). The mean "lowest" plasma iron value in 11 copper-deficient (i.m. iron) pigs was $62 \pm 7.3 \mu \mathrm{g} / 100 \mathrm{ml}$. The values are significantly different from one another $(P<0.01)$.

It should be noted that the hypoferremia in copper-deficient (i.m. iron) pigs was not a consequence of iron deficiency, since the total body iron concentration was normal and the iron storage sites were laden with iron in such animals (Table I). Thus, the ability to transfer iron from reticuloendothelial storage sites to plasma seemed to be impaired in copper-deficient animals.

Effect of an infusion of damaged erythrocytes on plasma iron. As another measure of the capacity of the reticuloendothelial system to process and release iron, the changes in plasma iron that followed the administration of damaged red cells 
were observed. Pig erythrocytes were damaged by storage at $4^{\circ} \mathrm{C}$ for a minimum of $3 \mathrm{wk}$, under aseptic conditions, in plasma containing heparin. An intravenous infusion that contained $1 \mathrm{mg}$ of iron as damaged erythrocytes per $\mathrm{kg}$ of body wt was administered to each of five control and eight copper-deficient pigs. The plasma iron was measured before the infusion and at intervals of $1,2,3$, and $4.5 \mathrm{hr}$ thereafter. In control animals, the plasma iron concentration increased markedly and reached a peak value at about $3 \mathrm{hr}$. In copper-deficient animals, on the other hand, the curves were relatively flat (Fig. 6).

Plasma iron after administration of copper. To obtain further evidence for an effect of copper on the release of iron from reticuloendothelial cells, the changes in plasma iron that followed the administration of copper to copper-deficient pigs were studied. In animals with anemia due to specific nutritional deficiencies, the plasma iron usually decreases when the deficient nutrient is supplied. By contrast, when copper $(0.1 \mathrm{mg} / \mathrm{kg}$ of

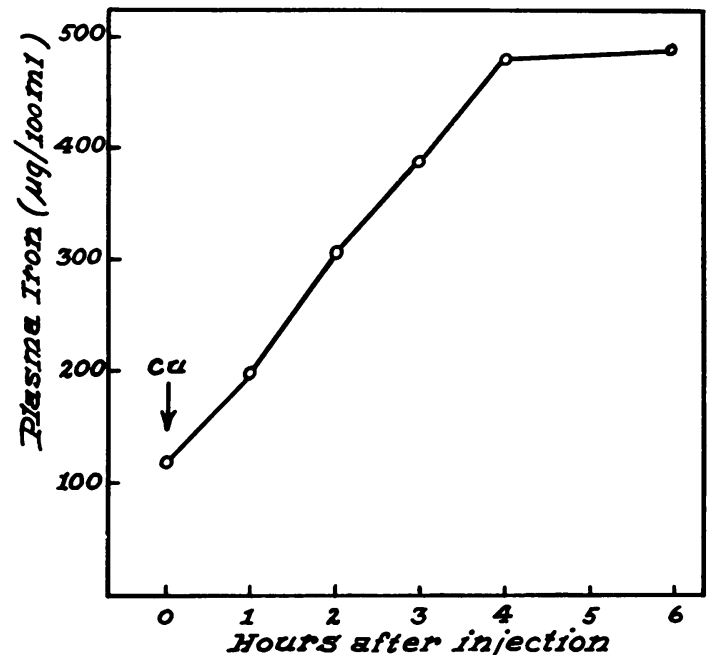

FIGURE 7 The effect of the administration of copper on the plasma iron in a copper-deficient pig.

body wt) was administered intravenously to copper-deficient (i.m. iron) pigs, the plasma iron concentration promptly increased and continued to

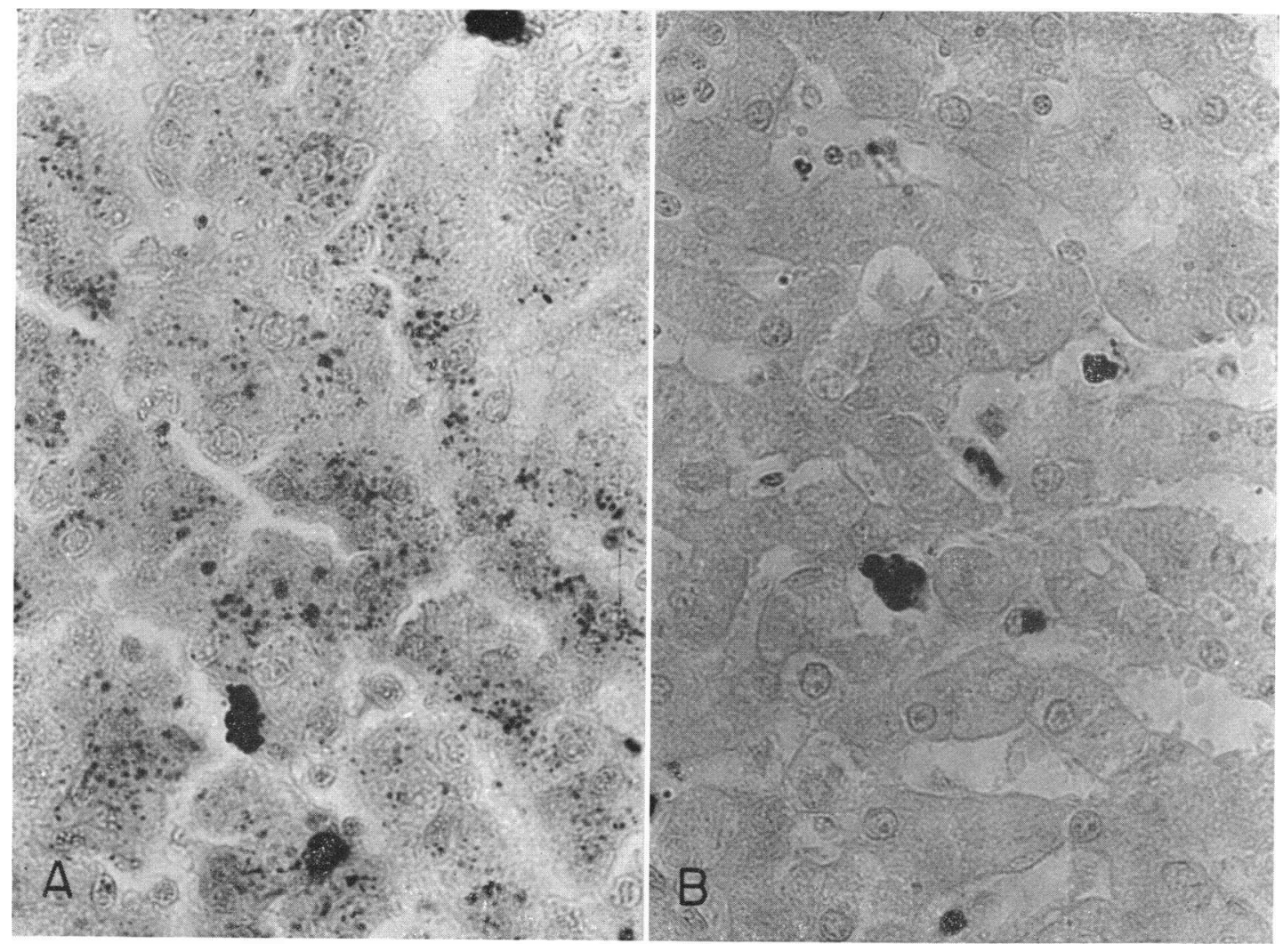

FIGURE 8 Iron stains of liver sections from a copper-deficient (I.M. iron) pig $(A)$ and a control pig $(B)$. Excessive parenchymal cell iron was observed in the copper-deficient animals. 
increase until the plasma iron-binding capacity was saturated (Fig. 7). Thus, copper administration appeared to remove an obstruction to the flow of iron from reticuloendothelial cells to plasma.

\section{The hepatic parenchymal cell}

The distribution of iron in hepatic cells was assessed in sections of liver stained by the Prussian blue technique. Sections of liver from five control and five copper-deficient animals were evaluated. Animals in both groups had received intramuscular iron supplements, and the concentration of liver iron was not significantly different in the two groups. In control animals, almost all stainable iron was confined to the Kupffer cells. A trace of hepatic parenchymal cell iron was seen in only one of the control animals. In contrast, all of the livers from copper-deficient animals contained parenchymal cell iron in addition to Kupffer cell iron. In three of these liver specimens, Kupffer and parenchymal cell iron was about equal, whereas in two, parenchymal cell iron exceeded that in the Kupffer cells. Representative photomicrographs from one pig in each group are shown in Fig. 8.

\section{Normoblast iron}

Toward the end of the observation period, plasma iron values in copper-deficient (i.m. iron) pigs increased to normal or above normal values without a coincident increase in the VPRC (Figs. 2 and 5). This phenomenon was not restricted to pigs receiving iron intramuscularly, but was also found in certain of the copper-deficient (oral iron)

TABLE III

Sideroblasts in Bone Marrow of CopperDeficient and Control Swine

\begin{tabular}{ccc}
\hline Group & No. & Sideroblasts \\
\hline $\begin{array}{c}\text { Controls } \\
\text { oral iron }\end{array}$ & 6 & $35.8 \pm 6.9$ \\
$\begin{array}{c}\text { Controls } \\
\text { i.m. iron }\end{array}$ & 6 & $36 \pm 6.9$ \\
$\begin{array}{c}\text { Copper Deficient } \\
\text { oral iron }\end{array}$ & 9 & $14.8 \pm 6.5$ \\
$\begin{array}{c}\text { Copper Deficient } \\
\text { i.m. iron }\end{array}$ & 8 & $76.6 \pm 8.3$ \\
\hline
\end{tabular}

Values are means \pm SEM. pigs, despite the fact that they were deficient in iron as well as copper. The plasma iron values at the end of the 12-17 wk observation period in 20 copper-deficient (oral iron) pigs appeared to fall into two, widely separated groups. In 13 of the pigs, the plasma iron value was "low," ranging from 13 to $53 \mu \mathrm{g} / 100 \mathrm{ml}$. In the remaining seven animals, the plasma iron value was "high," ranging from 132 to $247 \mu \mathrm{g} / 100 \mathrm{ml}$. The reticulocyte count in the "low iron" group was $7.9 \pm 1.0 \%$ (mean $\pm \mathrm{SEM}$ ), whereas in the "high iron" group, the reticulocyte count was $1.9 \pm 1.0 \%$. It appeared, therefore, that the terminal increase in serum iron might be related to decreased erythropoiesis, and that factors other than the supply of iron limited the response of the marrow.

To determine if such was the case, sideroblast counts were performed on bone marrow (Table III). A marked increase in the proportion of sideroblasts was observed in the bone marrows from copper-deficient (i.m. iron) pigs. Not only was the proportion of sideroblasts increased, but the amount of stainable iron in each sideroblast also appeared greater than in control animals. In sideroblasts from control animals, only one to three small granules were seen, whereas in the copperdeficient (i.m. iron) pigs, over half of the sideroblasts contained more than six granules. Moreover, individual iron granules appeared larger. No tendency was observed for the granules to form rings about the nucleus.

\section{DISCUSSION}

In these studies, as in others reported previously $(1,2)$, severe hypochromic, microcytic anemia developed in copper-deficient swine. The intramuscular administration of iron did not affect the rate at which anemia developed, nor did it prevent hypochromia and microcytosis.

Abnormalities of iron metabolism were observed in the duodenal mucosa, the reticuloendothelial system, the hepatic parenchymal cells, and in the normoblasts of copper-deficient swine. The first three of these tissues have in common the ability to do three things with iron. First, each can extract iron from some source; second, each can store iron to a variable extent; and third, each can release iron to the plasma. The abnormalities in iron metabolism that were observed in copper-deficient 
swine can best be explained by impaired ability of these three tissues to release iron.

Duodenal mucosa. On the basis of studies performed in vitro with rat duodenum, Manis and Schachter have suggested that iron absorption occurs in two distinct, energy-dependent steps (10). In step one, iron is extracted from the intestinal lumen by mucosa; in step two, mucosal iron is released into the blood stream. Our findings with radioactive test meals (Fig. 4) may be interpreted in terms of this hypothesis. The amount of dietary iron in the mucosa at any one time represents the difference between the iron extracted in step one and that released in step two. Thus, in control animals, the rate of transfer in step one exceeded that in step two for about 2-3 hr, and mucosal radioiron accumulated. Thereafter the transfer rate in step two exceeded step one, and the mucosal iron decreased. In copper-deficient pigs, the uptake of iron from duodenal lumen by mucosa appeared to be normal or increased. On the other hand, most of the iron accepted by the mucosa remained there over the $24 \mathrm{hr}$ observation period. Thus, iron taken up by mucosa was not subsequently released at the normal rate; step two was impaired.

The rate of iron transfer in step one appeared to be related to the status of the iron stores, since mucosal uptake was more rapid in iron-deficient than in control animals. This hypothesis may also account for the difference between the two copperdeficient groups. In copper-deficient (oral iron) pigs, step one was increased as a consequence of depleted iron stores; thus, a higher final plateau was reached (Fig. 4).

The expected end result of impaired mucosal iron release (step two) would be excessive mucosal iron storage. Excessive storage was, in fact, demonstrated (Fig. 3 and Table II), a particularly significant finding in the presence of a total body deficiency of iron.

Most of the iron retained by copper-deficient mucosa was probably in the form of ferritin (Table III). The fractionation method used allowed the recovery of a compound which was soluble, precipitable by reagents that precipitate protein, and resistant to heat denaturation. Studies with Sephadex gel exclusion and ultracentrifugation indicated that the compound was of high molecular weight. These properties, while not entirely specific for ferritin, are not characteristic of any other known biological iron compounds. The accumulation of ferritin in copper-deficient mucosa does not necessarily imply that copper is essential to ferritin iron release. Ferritin may not be a direct intermediate in the absorptive pathway, but simply a compound formed to protect the cell from damage by ionic iron during periods in which step one exceeds step two. It is interesting that in irondeficient pigs, at a time when both step one and step two were increased ( $2 \mathrm{hr}$ ), most of the iron was present in the nonprotein fraction of mucosal homogenates (Table II). It seems probable that the active transport form of iron across the cell wall is a nonprotein compound, possibly ionic iron itself.

Reticuloendothelial tissues. Reticuloendothelial (R-E) cells acquire iron by phagocytosis of senescent erythrocytes. The R-E system maintains the principal storage pool of iron, and constitutes the major source of supply of iron to the plasma. Under most circumstances, the plasma iron concentration reflects the balance between the rate at which iron is released from R-E cells and the rate at which iron is removed by tissues, especially the erythroid cells of the bone marrow. In copperdeficient pigs, the rate at which iron is removed from the plasma (the plasma iron turnover rate) is normal or nearly normal (11). Therefore, the hypoferremia with normal iron stores found in copper-deficient (i.m. iron) pigs implies that release of iron from $\mathrm{R}-\mathrm{E}$ cells is defective.

Evidence for this hypothesis was obtained by administering a "load" of iron in the form of damaged red cells. This test was used by Noyes, Bothwell, and Finch to evaluate "R-E iron block" in the anemia of infection (12). These workers reported that in normal human subjects the plasma iron level increased in a predictable manner after such an infusion, apparently because the iron from the infused cells was extracted by R-E tissues and promptly released. In the present studies, the changes in serum iron after infusion of damaged red cells into normal pigs resembled those which were observed in normal human subjects. On the other hand, little change in the plasma iron occurred in copper-deficient pigs after the infusion. This observation is consistent with the postulated defect in release of iron from R-E cells.

A prompt and steady increase in plasma iron 
occurred when copper was administered (Fig. 7). A similar response was observed in copper-deficient rats by Marston and Allen (13). These studies may be contrasted with observations made in cetrain other nutritional deficiencies, such as vitamin $B_{6}$ deficiency in swine (14), or in pernicious anemia in humans (15). In such disorders, the plasma iron decreases rapidly when the deficient nutrient is supplied, because the normoblasts withdraw iron from the plasma more rapidly than iron is introduced into the plasma. The increasing plasma iron observed in treated copperdeficient pigs suggests that iron flowed into plasma more rapidly than it flowed out. Since a hematopoietic response ensues in such animals (1), it seems improbable that the change which occurred on copper administration was a decrease in plasma clearance. Instead, an increase in flow of iron to plasma appears likely. The most reasonable interpretation of the phenomenon is that it reflects the correction of the defect in $\mathrm{R}-\mathrm{E}$ iron release. The iron could not have come from the intestine, since the animals studied had not received oral iron supplements; however, the hepatic perenchymal cell is a possible alternative source.

The expected end result of defective iron release would be accumulation of iron by $\mathrm{R}-\mathrm{E}$ tissues. Indeed, R-E iron storage was increased in copperdeficient (oral iron) pigs by comparison with irondeficient pigs with similar amounts of total body iron.

It appears, therefore, that the R-E cells in copper-deficient animals have an abnormality that is similar to the one found in mucosa. Iron release is impaired, consequently iron storage is increased.

The hepatic parenchymal cells. Hepatic cells receive iron directly from the plasma and return it to the same pool. No direct measurements were made of the rate of iron uptake or release by hepatic cells in copper-deficient pigs. However, excessive storage of iron by these cells was apparent (Table I, Fig. 8). This finding implies that at some point, iron uptake exceeded iron release. It seems likely that hepatic cells, like duodenal mucosa and R-E cells, have an impaired ability to release iron and that the excessive iron storage occurred for that reason. However, the possibility that the increased storage resulted from increased uptake of iron cannot be excluded.

The role of copper in iron metabolism. The failure of three different tissues to release iron normally in copper-deficient animals suggests that copper is essential to a biochemical reaction that results in the transfer of iron from cells to plasma and which is common to all three tissues. A1though the nature of the proposed copper dependent reaction is unknown, a reasonable hypothesis may be offered.

Iron is incorporated into apotransferrin only in the ferric state. Osaki, Johnson, and Frieden (16) have demonstrated that ceruloplasmin functions in vitro as a ferroxidase, and they have suggested that this enzyme may have a biological role in the incorporation of iron into transferrin according to the following reaction:

$$
\mathrm{Fe}^{++} \stackrel{\mathrm{C}}{\longrightarrow} \mathrm{Fe}^{+++}+\mathrm{ApoTf} \longrightarrow \mathrm{Tf}
$$

in which $\mathrm{C}$ refers to ceruloplasmin, ApoTf refers to apotransferrin, and $\mathrm{Tf}$ refers to transferrin.

A deficiency of ceruloplasmin is one of the earliest manifestations of copper deficiency (1). If duodenal mucosal cells, reticuloendothelial cells. and hepatic parenchymal cells transfer iron to their surfaces in the form of ferrous iron, this iron would not be oxidized to the ferric state, in the absence of ceruloplasmin, at a sufficiently rapid rate to allow for the normal movement of iron from these cells to the plasma. Such a hypothesis is quite compatible with the observation reported herein that the release of iron from these cells to plasma is impaired. A possible objection to this hypothesis is that patients with Wilson's disease and a deficiency of ceruloplasmin are not known to have abnormalities in iron metabolism.

Pathogenesis of the anemia. It is tempting to postulate that the anemia of copper deficiency is the consequence of an inadequate supply of iron to marrow, brought about by impaired release of iron from mucosal cells, reticuloendothelial cells, and hepatic parenchymal cells. However, this explanation seems unlikely since the hypoferremia observed in copper-deficient (i.m. iron) pigs was of brief duration and bore no clear temporal relation to the development of anemia (Fig. 5). Furthermore, late in the course of the deficiency, when the reticulocyte count and the volume of packed red cells continued to decline, the plasma iron level was frequently normal or increased. Finally, in conditions in which erythropoiesis is limited by the supply of iron available to the bone marrow, 
stainable normoblast iron is markedly reduced (17). By contrast, some normoblast iron was seen in copper deficient pigs, even in the group that received oral iron supplements. Moreover, normoblast iron was not only present, but markedly increased in the group that received intramuscular iron supplements. These observations would appear to exclude the possibility that iron-limited erythropoiesis is an adequate explanation for the anemia.

We propose, therefore, that an additional defect plays a role in the pathogenesis of the anemia of copper deficiency, and that this defect lies within the normoblast itself. Both the terminal rise in the plasma iron values and the increase in stainable normoblast iron could be explained by such a defect. Previous investigations failed to find evidence that the defect affected porphyrin or heme biosynthesis (3). In view of the defective metabolism of iron found in other tissues, it is possible that the defect in the normoblast also affects a biochemical reaction involving iron. If this is the case, it would be necessary to implicate a step involving intracellular iron metabolism rather than one connected with the transportation of iron across a cell wall. Such a defect might result in the accumulation of iron in a form that could not be incorporated into hemoglobin.

\section{ACKNOWLEDGMENTS}

The authors would like to thank Dr. Wayne H. Linkenheimer of the American Cyanamid Company for supplying the intramuscular iron preparation used in these studies and Dr. Fenimore T. Johnson of the Upjohn Company for supplying heparin for use as an anticoagulant. The technical assistance of Miss Jacqueline Thomas, Mrs. Alice Tustison, and Mrs. Barbara Halliday is gratefully acknowledged.

This investigation was supported in part by Research grant AM-04489 and Training grant AM-5098 from the National Institute of Arthritis and Metabolic Diseases, National Institutes of Health, Bethesda, Md.

\section{REFERENCES}

1. Lahey, M. E., C. J. Gubler, M. S. Chase, G. E. Cartwright, and M. M. Wintrobe. 1952. Studies on copper metabolism. II. Hematologic manifestations of copper deficiency in swine. Blood. 7: 1053.

2. Cartwright, G. E., C. J. Gubler, J. A. Bush, and M. M. Wintrobe. 1956. Studies on copper metabolism. XVII. Further observations on the anemia of copper deficiency in swine. Blood. 11: 143.

3. Lee, G. R., G. E. Cartwright, and M. M. Wintrobe. 1968. Heme biosynthesis in copper deficient swine. Proc. Soc. Exptl. Biol. Med. 127: 977.

4. Gubler, C. J., M. E. Lahey, M. S. Chase, G. E. Cartwright, and M. M. Wintrobe. 1952. Studies on copper metabolism. III. The metabolism of iron in copper deficient swine. Blood. 7: 1075.

5. Cartwright, G. E. 1968. Diagnostic Laboratory Hematology. Grune and Stratton, New York. 4th edition.

6. Gömöri, G. 1936. Microtechnical demonstration of iron. A criticism of its methods. Am. J. Pathol. 12: 655.

7. Andersen, D., and W. C. Shoemaker. 1965. Method for tissue hemoglobin analysis. Clin. Chem. 11: 422.

8. Bush, J. A., W. N. Jensen, G. E. Cartwright, and M. M. Wintrobe. 1955. Blood volume studies in normal and anemic swine. Am. J. Physiol. 181: 9.

9. Brown, E. B., and M. L. Rother. 1963. Studies on the mechanism of iron absorption. I. Iron uptake by the normal rat. J. Lab. Clin. Med. 62: 357.

10. Manis, J. G., and D. Schachter. 1962. Active transport of iron by intestine: features of the two-step mechanism. Am. J. Physiol. 203: 73.

11. Bush, J. A., W. N. Jensen, J. W. Athens, H. Ashenbrucker, G. E. Cartwright, and M. M. Wintrobe. 1956. Studies on copper metabolism. XIX. The kinetics of iron metabolism and erythrocyte lifespan in copper deficient swine. J. Exptl. Med. 103: 701.

12. Noyes, W. D., T. H. Bothwell, and C. A. Finch. 1960. The role of the reticulo-endothelial cell in iron metabolism. Brit. J. Haematol. 6: 43.

13. Marston, H. R., and S. H. Allen. 1967. Function of copper in the metabolism of iron. Nature. 215: 645 .

14. Cartwright, G. E., and M. M. Wintrobe. 1948. Studies on free erythrocyte protoporphyrin, plasma copper, and plasma iron in normal and in pyridoxine-deficient swine. J. Biol. Chem. 172: 557.

15. Hawkins, C. F. 1955. Value of serum iron levels in assessing effect of haematinics in the macrocytic anaemias. Brit. Med. J. 1: 383.

16. Osaki, S., D. A. Johnson, and E. Frieden. 1965. The possible significance of the ferrous oxidase activity of ceruloplasmin in normal human serum. J. Biol. Chem. 241: 2746 .

17. Bainton, D. F., and C. A. Finch. 1964. The diagnosis of iron deficiency anemia. Am. J. Med. 37:62. 